\title{
GESTÃO UNIVERSITÁRIA: POLÍTICAS COMPARADAS DE MONITORAMENTO DO PROGRAMA BOLSA PERMANÊNCIA EM UNIVERSIDADES FEDERAIS BRASILEIRAS
}

\author{
GESTIÓN UNIVERSITARIA: POLITICAS COMPARATIVAS DE MONITOREO DEL \\ PROGRAMA DE BECAS DE PERMANENCIA EN UNIVERSIDADES FEDERALES \\ BRASILEÑAS
}

\section{UNIVERSITY MANAGEMENT: COMPARATIVE POLICIES OF MONITORING OF THE SCHOLARSHIP PROGRAM IN BRAZILIAN FEDERAL UNIVERSITIES}

\author{
Adriana Carla Teixeira da Costa BRITO ${ }^{1}$ \\ Ana Karoliny Teixeira da COSTA ${ }^{2}$ \\ Vera Luci de ALMEIDA ${ }^{3}$
}

RESUMO: O presente artigo estabelece uma discussão sobre a necessidade de se criar mecanismos de monitoramento e avaliação para o Programa Nacional de Assistência Estudantil (PNAES), em universidades federais brasileiras. Em específico, toma-se por objetivo investigar os instrumentos de monitoramento e avaliação do Programa de Bolsa Permanência, implantado em cinco universidades federais, a saber: UFAC, UFPR, UFS, UFU e UFV. A seleção feita toma como base a análise de dados obtidos em auditorias da Controladoria Geral da União (CGU), por meio do Relatório de Avaliação dos Resultados da Gestão no 201601866/CGU; os quais apontam a presença de tais instrumentos somente nessas universidades. No presente estudo, adotam-se as metodologias qualitativa e survey, como mecanismos para obter dados e informações de um determinado grupo. A partir dessa análise, foi possível observar, entre outros aspectos, que as universidades pesquisadas desenvolvem a política de monitoramento das ações de Assistência Estudantil, a fim de atender não apenas ao inciso II, do artigo $5^{\circ}$, do Decreto $n^{\circ} 7.234 / 2010$, que prevê a execução de monitoramento e avaliação do programa; mas também, para obtenção de informações durante o processo, com vistas a possibilitar possíveis ajustes da política local, de forma imediata.

PALAVRAS-CHAVE: Políticas Públicas. Ensino Superior. Avaliação. Controle Social.

RESUMEN: Este documento discute la necesidad de crear mecanismos de monitoreo y evaluación para el Programa Nacional de Asistencia al Estudiante (PNAES) en las universidades federales brasileñas. Específicamente, el objetivo es investigar los instrumentos de monitoreo y evaluación del Programa de Becas de Permanencia, implementado en cinco universidades federales, a saber: UFAC, UFPR, UFS, UFU y UFV. La selección realizada se basa en el análisis de los datos

\footnotetext{
${ }^{1}$ Universidade Federal da Grande Dourados (UFGD), Dourados - MS - Brasil. Mestra em Administração Pública, PROFIAP/UFGD. Assistente em Administração da UFGD - Dourados (COGRAD/PROGRAD). ORCID: https://orcid.org/0000-0002-3356-0456. E-mail: adrianacarlacosta@gmail.com

${ }^{2}$ Universidade Federal da Grande Dourados (UFGD), Dourados - MS - Brasil. Mestra em Letras, PPGL/UFGD, Dourados - MS - Brasil. Assistente em Administração da UFMS - Campo Grande (CDA/PROGRAD/DIPEC). ORCID: https://orcid.org/0000-0001-8604-6621.E-mail: karoliny_costa@hotmail.com

${ }^{3}$ Universidade Federal da Grande Dourados (UFGD), Dourados - MS - Brasil. Docente associada. Doutora em Engenharia e Gestão do Conhecimento pela Universidade Federal de Santa Catarina (2009). ORCID: https://orcid.org/0000-0003-1020-9169. E-mail: vera.vla@gmail.com
} 
obtenidos en auditorías de la Contraloría General de la Unión (UGE), a través del Informe de Evaluación de Resultados de la Gestión No. 201601866 / UGE; que señalan la presencia de tales instrumentos solo en estas universidades. En el presente estudio, las metodologías cualitativas y de encuesta se adoptan como mecanismos para obtener datos e información de un grupo en particular. A partir de este análisis, fue posible observar, entre otros aspectos, que las universidades investigadas desarrollan la política de monitoreo de las acciones de Asistencia al Estudiante, para no solo cumplir con el ítem II, artículo 5, del Decreto No. 7.234 / 2010, que prevé la ejecución del seguimiento y evaluación del programa; pero también para obtener información durante el proceso, con el fin de permitir posibles ajustes de la política local, de inmediato.

PALABRAS CLAVE: Políticas públicas. Enseñanza superior. Evaluación. Control social

ABSTRACT: This paper discusses the need to create monitoring and evaluation mechanisms for the National Student Assistance Program (PNAES) in Brazilian federal universities. Specifically, the objective is to investigate the monitoring and evaluation instruments of the Permanence Scholarship Program, implemented in five federal universities, namely: UFAC, UFPR, UFS, UFU and UFV. The selection made is based on the analysis of data obtained in audits of the Comptroller General of the Union (CGU), through the Management Results Evaluation Report No. 201601866 / $C G U$; which point out the presence of such instruments only in these universities. In the present study, the qualitative and survey methodologies are adopted as mechanisms to obtain data and information from a particular group. From this analysis, it was possible to observe, among other aspects, that the researched universities develop the policy of monitoring Student Assistance actions, in order not only to comply with item II, article 5, of Decree No. 7.234 / 2010, which provides for the execution of program monitoring and evaluation; but also to obtain information during the process, with a view to enabling possible local policy adjustments, immediately.

KEYWORDS: Public policy. University education. Evaluation. Social control.

\section{Introdução}

O presente artigo busca fazer uma abordagem acerca da Política de Assistência Estudantil Brasileira, desenvolvida nas Instituições Federais de Ensino Superior (IFES), a partir dos anos 2000. Mais especificamente, toma-se como objetivo investigar quais instrumentos são utilizados para avaliar e monitorar os Programas de Assistência Estudantil das IFES, ou ainda, como se procurará mostrar, cabe indagar se de fato esses instrumentos existem e, quando presentes, se desempenham o seu papel de modo satisfatório.

Tal investigação tem como base parte dos resultados de pesquisa coletados durante o mestrado em Administração Pública (PROFIAP/UFGD), no ano de 2018, por Adriana Carla Teixeira da Costa Brito, uma das autoras do presente artigo. Na época, Brito (2018) lançou mãos de recursos metodológicos, tais como: a feitura de questionários on line com alunos beneficiários de Programa de Assistência Estudantil, assim como com servidores e professores das IFES; também houve a preocupação em acessar o acervo documental expedido pelas instituições, relacionado ao 
tema de pesquisa; buscou-se fazer o levantamento de dados documentais registrados em atas de reuniões que tomavam como pauta a preocupação com políticas educacionais, a exemplo do trabalho realizado pelo Fórum Nacional de Pró-Reitores de Assuntos Comunitários e Estudantis (FONAPRACE); e, somado a isso, procurou-se dialogar com as Leis que foram criadas ao longo dos anos, de acordo com as perspectivas sociopolíticas e econômicas adotadas no país; bem como, buscou-se apoio na literatura que se tem sobre políticas públicas.

No presente momento, a reflexão a que se propõe neste artigo parte de uma análise dos dados obtidos, ao tomar como referência teóricos, tais como: Alves (2002), Secchi (2010), Arretche (2009), entre outros. Esses teóricos são responsáveis por enfatizar a importância não somente da implantação de políticas de assistência estudantil, enquanto parte de uma política pública, mas pressupõem a necessidade da criação de ferramentas que auxiliem na avaliação e no monitoramento dessas políticas, com vistas ao alcance de melhores resultados, em termos de otimização do atendimento do seu público-alvo, bem como do melhor aproveitamento possível do recurso destinado a determinado programa.

Como se procurará mostrar ao longo do texto, é a partir da leitura deste material, aliado à leitura do relatório da Controladoria Geral da União (CGU) dos anos de 2015 e 2016, que se defrontou com a seguinte questão: nem todas as universidades federais possuem instrumentos de monitoramento.

Tal Relatório aponta que 58 universidades federais passaram por auditoria da CGU, a fim de demonstrar a aderência do PNAES nas universidades federais e verificar a atuação dos envolvidos no processo daquilo que os compete. Além disso, buscou-se assegurar o impacto social do programa em relação à permanência de estudantes socioeconomicamente vulneráveis na educação superior, com o objetivo de averiguar a redução das taxas de evasão e retenção. Como resultado das auditorias, a própria CGU fez a consolidação dos relatórios das universidades federais e, em síntese, constatou que apenas 10,3\% realizam a avaliação dos resultados do PNAES, ou seja, 89,7\% das universidades não cumprem a previsão do inciso II do art. $5^{\circ}$ do Decreto $\mathrm{n}^{\circ} 7.234 / 2010$, que estabelece a necessidade de monitoramento e avaliação dos Programas. Assim, do total de 58 universidades auditadas, apenas cinco apresentam alguma forma de monitoramento e avaliação, ou seja, apenas as universidades: Universidade Federal do Acre (UFAC), Universidade Federal do Paraná (UFPR), Universidade Federal de Sergipe (UFS), Universidade Federal de Uberlândia (UFU) e Universidade Federal de Viçosa (UFV). 


\section{Política de Assistência Estudantil na Educação Superior}

Mediante a expansão da Educação Superior, ocorrida a partir dos anos 2000, e a reserva de cotas para ingresso nas universidades, modificou-se o perfil dos estudantes, de forma a possibilitar o ingresso de alunos de classes socioeconômicas mais baixas, o que tornou essencial o fortalecimento das ações de assistência estudantil, com o propósito de minimizar as dificuldades dos graduandos em situação de vulnerabilidade socioeconômica.

Com isso, surge ao final do ano de 2007 o Programa Nacional de Assistência Estudantil (PNAES), instituído pela Portaria Normativa $\mathrm{n}^{\circ} 39$, de 12 de dezembro de 2007, e pelo Decreto $\mathrm{n}^{\circ}$ 7.234, de 19 de julho de 2010, com o objetivo de garantir a permanência do aluno na instituição, combater a evasão e a retenção, além de propiciar condições de igualdade.

Para Alves (2002, p. 1), a Política de Assistência Estudantil “[...] tem como finalidade prover recursos necessários para transposição dos obstáculos e superação dos impedimentos ao bom desempenho acadêmico [...]". Dessa forma, a assistência transita em todas as áreas dos direitos humanos e compreende ações que proporcionam condições de saúde, instrumentos pedagógicos necessários e recursos mínimos para a sobrevivência, tais como, moradia, transporte, alimentação, cultura, lazer e outros.

Nesse sentido, por se tratar de uma política pública, a Assistência Estudantil precisa fazer uso de alternativas para o seu fortalecimento, que consiste em processos sistemáticos de avaliação e, por conseguinte, incide em um melhor planejamento e desenvolvimento das ações de assistência ao estudante, desenvolvidas nas Universidades.

Assim, uma vez entendida como uma política pública, a execução da assistência estudantil necessita das etapas planejamento, implementação, monitoramento e avaliação, o chamado ciclo de políticas públicas (SECCHI, 2010).

A teoria do ciclo das políticas públicas tenta explicar a interação entre intenções e ações, ao mesmo tempo em que busca desvendar a relação entre o ambiente social, político e econômico, de um lado, e o governo, de outro. As ações no campo da política pública e os saberes técnicos a ela associados se definem a partir de inúmeras decisões que são tomadas e estão permeadas por paradoxos. Essas ações partem de um conjunto de pressupostos que determinam a atribuição de responsabilidades, a seleção dos assuntos relevantes, as alternativas a serem adotadas, a avaliação de necessidades e a formação do público-alvo (SECCHI, 2010).

Segundo Arretche (2009), é possível perceber nos estudos concernentes ao PNAES a preocupação com as etapas de planejamento e implementação, porém, há escassez de informações no que se refere ao monitoramento e avaliação do programa. Para o autor, a avaliação e o 
monitoramento a determinado programa implicam em um processo de desconstrução, reflexão, crítica e organização de uma prática melhor, ao mesmo tempo em que transforma as relações entre os sujeitos.

Sobre esse ponto, Silva e Melo (2000), ao falar sobre o ciclo de políticas públicas, afirma que se trata de um processo e, como tal, deve estar munido de medidas que visem retroalimentar a etapa de formulação e corrigir eventuais desvios durante a fase de implementação, conforme demonstra a Figura 1:

Figura 1 - A visão do policy cycle como um processo simples e linear

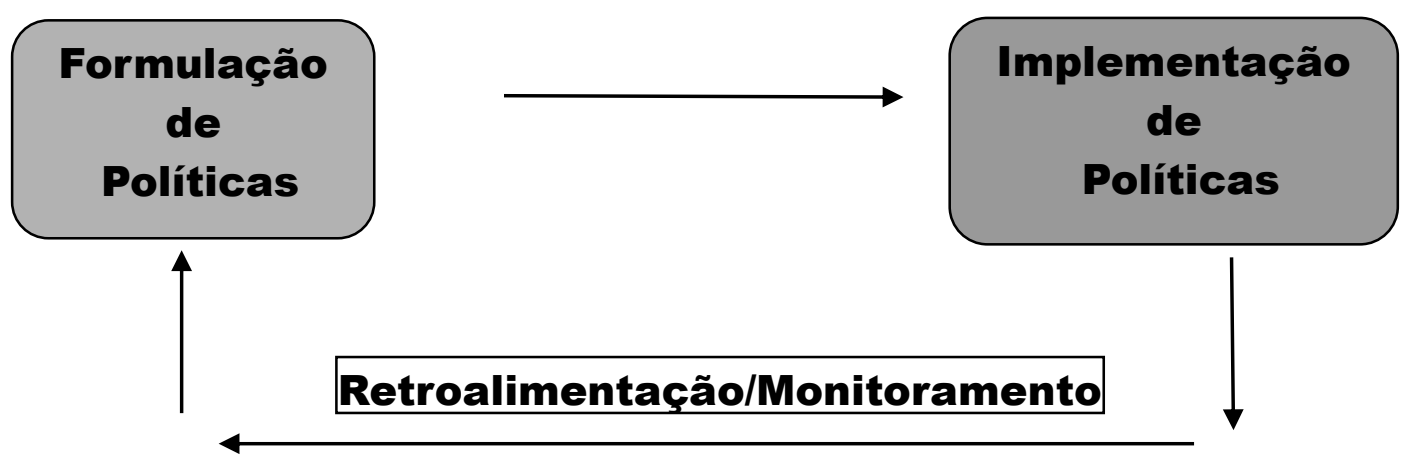

Fonte: Silva e Melo (2000, p. 6).

Dessa forma, torna-se imprescindível que sejam realizadas as avaliações das políticas públicas, tendo em vista a possibilidade que essas ações proporcionam de corrigir e aperfeiçoar a política em andamento. Dentro dessa perspectiva, com a implantação do PNAES surge, então, a necessidade de verificar a sua efetividade, a partir do acompanhamento local e nacional, a fim de estabelecer uma relação de causalidade entre a política pública e as transformações observadas.

Nesse contexto, em diálogo com Secchi (2010), se observa que o monitoramento e avaliação de políticas públicas se tornaram essenciais para o planejamento governamental. Uma vez que, com a avaliação da política pública, torna-se possível construir uma ferramenta adequada para a transparência e prestação de contas das ações governamentais à sociedade.

\section{Monitoramento e avaliação da Assistência Estudantil}

Segundo Arretche (2009), avaliar pressupõe determinar a valia ou o valor de algo; exige apreciar ou estimar o merecimento, a grandeza, a intensidade ou a força de uma política social 
diante da situação a que se destina. Avaliar significa estabelecer uma relação de causalidade entre um programa e seu resultado. Isto só pode ser obtido mediante o estabelecimento de uma relação causal entre a modalidade da política social avaliada e seu sucesso e/ou fracasso, tendo como parâmetro a relação entre objetivos, intenção, desempenho e alcance dos objetivos. Nesse contexto, Condé (2013) ressalta que, para um monitoramento e uma avaliação efetivos, é necessária a previsão desses no desenho da política.

Battistuz (2014) enfatiza que, da necessidade de definir os critérios de avaliação, faz-se indispensável à definição da forma como estes critérios serão monitorados. Trata-se, assim, do processo de definição de indicadores. Os principais requisitos para o monitoramento e a avaliação de políticas públicas são os indicadores e suas composições que oferecem informações consistentes para que sejam traçadas as melhores decisões. Para Fernandes (2014), o sistema de indicadores deve conter informações de diferentes fontes e ser organizado de modo sintético para os gestores e, além disso, contar com indicadores que permitam a análise comparativa das informações ao longo do tempo, de forma que, ao analisar o comportamento dos indicadores em um intervalo de tempo, é possível identificar falhas operativas do programa.

Segundo Buvinich (1999), um bom indicador deve apresentar algumas características, conforme apresentadas no Quadro 1.

\section{Quadro 1 - Características dos indicadores}

\begin{tabular}{|l|l|}
\hline Indicador & Característica \\
\hline Válido & Que meça o que se supõe deve ser medido \\
\hline Confiável & Que seja verificável \\
\hline Relevante & Aos objetivos do programa/projeto \\
\hline Sensitivo & Às mudanças da situação que é observada \\
\hline Aceitável & Pela população em estudo e pelos que coletam a informação \\
\hline Específico & Adaptado aos objetivos do programa/projeto \\
\hline Oportuno & Que possa ser constituído e reportado em tempo hábil \\
\hline $\begin{array}{l}\text { Tecnicamente } \\
\text { viável }\end{array}$ & $\begin{array}{l}\text { Viável: que os dados requeridos possam ser coletados e mensuráveis (i.e., fácil de } \\
\text { coletar através da amostragem, disponibilidade de pessoal especializado, } \\
\text { disponibilidade transporte do equipamento necessário, etc.) }\end{array}$ \\
\hline Custo-efetivo & $\begin{array}{l}\text { Que os dados requeridos possam ser coletados a um custo razoável (i.e., custos de } \\
\text { capital, pessoal, operacionais) }\end{array}$ \\
\hline
\end{tabular}

Fonte: Buvinich (1999)

Mediante as características dispostas no Quadro 1, é importante observar a escolha dos indicadores, a facilidade, a oportunidade e o papel da discriminação na sua construção. Há, contudo, que se respeitar as características desejáveis que os indicadores devam ter. 
Nesse sentido, entende-se que esse instrumento de acompanhamento e avaliação deverá ser capaz de apontar novas possibilidades para o programa de assistência estudantil de uma IFES, tanto no que diz respeito à concessão de auxílio quanto ao fortalecimento do programa na instituição. Ademais, permitirá agregar informações referentes ao desenvolvimento do estudante e a aplicação dos recursos financeiros, de forma a possibilitar que os gestores tomem decisões qualificadas sobre a necessidade da destinação dos recursos.

Portanto, a avaliação e o monitoramento permitem conhecer a política a fundo, de modo a identificar os seus pontos fortes e fracos, sendo fundamental para a qualificação das decisões. Além disso, possibilita verificar se os objetivos traçados foram alcançados.

\section{Metodologia}

O presente estudo trata-se de uma pesquisa de caráter qualitativo. E segundo Creswell (2007), a investigação qualitativa emprega diferentes alegações de conhecimento, estratégias de investigação e métodos de coleta e análise de dados. Ou seja, nos estudos qualitativos, os investigadores coletam formas múltiplas de dados e gastam um tempo considerável no ambiente natural reunindo informações do tipo: observações, nas quais o pesquisador toma notas de campo sobre comportamento e atividades das pessoas no local de pesquisa; entrevistas, o pesquisador conduz entrevistas face a face com os participantes, entrevista os participantes por telefone ou faz entrevistas com grupos focais, com 6 a 8 entrevistados em cada grupo e documentos. Durante o processo de pesquisa, o investigador qualitativo pode coletar documentos, que podem ser documentos públicos ou documentos privados (CRESWELL, 2007).

E também, uma pesquisa survey, que pode ser descrita como a obtenção de dados ou informações sobre características, ações ou opiniões de determinado grupo de pessoas, sendo indicado - como representante de uma população-alvo, por meio de um instrumento de pesquisa, normalmente um questionário.

Para obter informações do processo de monitoramento em outras universidades realizou-se uma pesquisa pontual nas 5 universidades que realizam o processo: Acre (UFAC), do Paraná (UFPR), de Sergipe (UFS), de Viçosa (UFV) e de Uberlândia (UFU). O questionário contém 27 questões e foi enviado via Sistema Eletrônico do Serviço de Informações ao Cidadão (e-SIC). O questionário tem predominância de múltipla escolha, além de oito questões abertas e uma com "caixa de seleção".

As categorias analisadas foram: a estrutura em que está inserido o PNAES; fatores 
específicos que caracterizam o Programa Bolsa Permanência; a aplicabilidade do monitoramento e avaliação em fatores como desempenho, permanência, taxa de evasão e retenção dos alunos; principais dificuldades encontradas e proposição de sugestões.

O contato com as universidades foi realizado através de e-mails, retirados da página eletrônica das instituições, dos quais se priorizou o setor responsável pelo PNAES. Os questionários foram respondidos no período de setembro/2018 e outubro/2018. Logo, das cinco universidades que fizeram parte do campo de pesquisa, quatro responderam ao contato e disponibilizaram os dados solicitados.

Por fim realizou-se a análise e discussão dos dados, que segundo Creswell (2007) inclui preparar os dados para análise, conduzir análises diferentes, aprofundar-se cada vez mais no entendimento dos dados, fazer representação dos dados e fazer uma interpretação do significado mais amplo dos dados. A partir deste entendimento, após a coleta dos dados, os mesmos foram dispostos e tratados em uma planilha do Excel, e dessa base construído o corpus de análise da pesquisa, em que foram verificadas as propostas de monitoramento e avaliação do PNAES.

\section{Os processos de avaliação e monitoramento nas universidades auditadas}

A Universidade Federal do Acre (UFAC), Universidade Federal do Paraná (UFPR), Universidade Federal do Sergipe (UFS), Universidade Federal de Viçosa (UFV) e Universidade Federal de Uberlândia (UFU) são as responsáveis por realizar em seus domínios formas de monitoramento e avaliação do PNAES, segundo dados do Relatório de Avaliação dos Resultados da Gestão no 201601866/CGU. Ao que diz respeito ao monitoramento da Política de Assistência Estudantil nas universidades federais, há de se destacar um aspecto importante que é o estudo e análises relativas à demanda social da comunidade local - apontado no Decreto 7.234/2010, como de relevante importância a ser observado.

$\mathrm{Na}$ análise dos dados, apenas a UFAC aponta fazer o estudo sempre que necessário. Outro aspecto importante a ser destacado é a utilização de um sistema capaz de gerar relatórios necessários para a análise dos indicadores. Apenas a UFS relata ter um sistema que produza essas informações automaticamente. Entretanto, a UFAC e UFV enfatizam que as informações são geradas parte por sistema e parte manualmente.

Quando questionadas sobre a utilização de algum instrumento de avaliação e monitoramento dos resultados do programa, as universidades UFAC e UFS apontam que se utilizam frequentemente de instrumentos e que ainda possuem indicadores específicos para o 
acompanhamento desses. Por outro lado, a universidade UFU relata não ter até o momento e a UFV está em fase de construção.

Sobre esse assunto, Battistuz (2014) enfatiza que, da necessidade de definir os critérios de avaliação, faz-se necessária a definição da forma como estes critérios serão monitorados. Trata-se, assim, do processo de definição de indicadores. Os principais requisitos para o monitoramento e a avaliação de políticas públicas são os indicadores e suas composições que oferecem informações consistentes para que sejam traçadas as melhores decisões.

Para Fernandes (2014), o sistema de indicadores deve conter informações de diferentes fontes e ser organizado de modo sintético para os gestores e, além disso, contar com indicadores que permitam a análise comparativa das informações ao longo do tempo, de forma que, ao analisar o comportamento dos indicadores em um intervalo de tempo, é possível identificar falhas operativas do programa.

Encontra-se na pesquisa o predomínio da importância do estabelecimento de normas ou regulamentos e a definição dos critérios a serem monitorados. Condé (2013) ressalta que, para um monitoramento e uma avaliação efetivos, é necessária a previsão desses no desenho da política.

Quanto à permanência, as universidades foram questionadas sobre a preocupação em medir a taxa de evasão e retenção dos alunos, conforme os objetivos do Decreto $n^{\circ} 7.234 / 2010$. Nesse aspecto, a UFAC relata que está em fase de construção de um observatório para a análise. Já as demais universidades, relatam que medem as taxas semestralmente e ou anualmente.

Logo, quando questionados quanto ao monitoramento do desempenho, as quatro universidades relataram fazer o acompanhamento. Justificada a importância dessa ação, pois os modelos de avaliação de desempenho devem incorporar um conjunto de indicadores de desempenho, visando a assegurar o alinhamento das atividades com o objetivo maior da organização. Para que a medição de desempenho atinja os seus objetivos, com maior eficiência e eficácia, ela deve estar alicerçada aos princípios da universidade.

No tocante à análise da relação entre o desempenho e a permanência dos alunos na instituição, apenas a UFAC diz que não o faz. Em tal situação, apenas a avaliação se preocupa com seus efeitos e implicações na realidade. Para Arretche (2009, p. 39):

[...] ainda que a análise de uma política pública possa atribuir a um determinado desenho institucional alguns resultados prováveis, somente a avaliação desta política poderá atribuir uma relação de causalidade entre um programa $\mathrm{X}$ um resultado. 
Assim como a necessidade que se dá na avaliação do beneficiário em relação ao programa, quando questionados sobre a prática de conceder voz ao estudante, apenas a UFU enfatiza que realiza tal ação, na qual possam conhecer a visão dos beneficiários da política de assistência estudantil e suas necessidades e, assim, incorporar sugestões desses para melhorar a gestão do Programa. Na visão de Arretche (2009), avaliar significa estabelecer uma relação de causalidade entre um programa e seu resultado, dito isso, entende-se que a partir da avaliação do beneficiário do programa as ações serão consolidadas e tratadas as suas falhas, tendo como parâmetro a relação entre objetivos, intenção, desempenho e alcance dos objetivos.

O Quadro 2 disponibiliza as respostas da pesquisa nas universidades na íntegra e enfatiza cada qual a sua realidade.

Quadro 2 - Resultado da pesquisa nas Universidades Federais sobre o monitoramento do PNAES (UFAC, UFS, UFU, UFV)

\begin{tabular}{|c|c|c|c|c|c|}
\hline \multicolumn{2}{|r|}{ QUESTÃO } & UFAC & UFS & UFU & UFV \\
\hline 1 & $\begin{array}{lrr}\text { O setor } & \text { responsável } & \text { pelo } \\
\text { Programa } & \text { Nacional } & \text { de } \\
\text { Assistência } & \text { Estudantil } \\
\text { (PNAES) } & & \\
\end{array}$ & Pró-Reitoria & Pró-Reitoria & Pró-Reitoria & Pró-Reitoria \\
\hline 2 & $\begin{array}{l}\text { Por quem é feito o } \\
\text { planejamento da distribuição } \\
\text { do recurso orçamentário } \\
\text { entre as ações do PNAES }\end{array}$ & $\begin{array}{l}\text { Unidade } \\
\text { administrativa }\end{array}$ & $\begin{array}{l}\text { Unidade } \\
\text { administrativa }\end{array}$ & $\begin{array}{l}\text { Unidade } \\
\text { administrativ } \\
\text { a }\end{array}$ & $\begin{array}{l}\text { Setor } \\
\text { responsável } \\
\text { pelo } \\
\text { orçamento }\end{array}$ \\
\hline 3 & $\begin{array}{l}\text { A escolha das áreas de } \\
\text { atuação dos recursos do } \\
\text { PNAES roram } \\
\text { fundamentadas em estudos e } \\
\text { análises relativos à demanda } \\
\text { social }\end{array}$ & Sempre & Regularmente & $\begin{array}{l}\text { Regularment } \\
\mathrm{e}\end{array}$ & Regularmente \\
\hline 4 & $\begin{array}{l}\text { A IES realiza estudos e } \\
\text { análises para fundamentar a } \\
\text { aplicação dos recursos do } \\
\text { PNAES? }\end{array}$ & $\begin{array}{l}\text { Sim, todos os } \\
\text { anos }\end{array}$ & $\begin{array}{l}\text { Sim, todos os } \\
\text { anos }\end{array}$ & $\begin{array}{l}\text { Sim, todos os } \\
\text { anos }\end{array}$ & Parcialmente \\
\hline 5 & $\begin{array}{l}\text { A IES possui um sistema } \\
\text { informatizado para a gestão, } \\
\text { avaliação e monitoramento } \\
\text { dos programas? }\end{array}$ & $\begin{array}{l}\text { Ambos (parte } \\
\text { informatizada } \\
\text { e parte não } \\
\text { informatizada }\end{array}$ & Sim & Não & $\begin{array}{l}\text { Ambos (parte } \\
\text { informatizada } \\
\text { e parte não } \\
\text { informatizada }\end{array}$ \\
\hline 6 & $\begin{array}{l}\text { Dentre as ações do PNAES } \\
\text { desenvolvidas na IES, existe } \\
\text { algum programa, exceto o } \\
\text { Programa Bolsa Permanência } \\
\text { do MEC, que conceda o } \\
\text { benefício financeiro aos } \\
\text { estudantes em situação de } \\
\text { vulnerabilidade } \\
\text { socioeconômica, com a } \\
\text { finalidade de minimizar as } \\
\text { desigualdades sociais entre } \\
\text { os estudantes e garantir a } \\
\text { permanência desses, na }\end{array}$ & Sim & Sim & Sim & Sim \\
\hline
\end{tabular}




\begin{tabular}{|c|c|c|c|c|c|}
\hline & Instituição? & & & & \\
\hline 7 & $\begin{array}{l}\text { A IES possui instrumentos de } \\
\text { avaliação e monitoramento } \\
\text { dos resultados do Programa } \\
\text { Bolsa } \\
\text { Institucional? }\end{array}$ & $\begin{array}{l}\text { Sim, e estão } \\
\text { sendo } \\
\text { executados }\end{array}$ & $\begin{array}{l}\text { Sim, e estão } \\
\text { sendo } \\
\text { executados }\end{array}$ & $\begin{array}{lr}\text { Não, mas } \\
\text { estamos em } \\
\text { fase de } \\
\text { elaboração }\end{array}$ & $\begin{array}{lr}\text { Não, mas } \\
\text { estamos } & \text { em } \\
\text { fase } & \text { de } \\
\text { elaboração }\end{array}$ \\
\hline 8 & $\begin{array}{l}\text { A IES possui indicadores e } \\
\text { metas específicas para o } \\
\text { acompanhamento } \\
\text { Programa Bolsa Permanência } \\
\text { Institucional? }\end{array}$ & Sim & Sim & Não & $\begin{array}{l}\text { Parcialmente, } \\
\text { estamos em } \\
\text { fase de } \\
\text { construção }\end{array}$ \\
\hline 9 & $\begin{array}{l}\text { A IES possui o controle dos } \\
\text { pagamentos concedidos, aos } \\
\text { estudantes beneficiados com } \\
\text { o Programa Bolsa } \\
\text { Permanência Institucional? }\end{array}$ & $\begin{array}{l}\text { Sim, de todos } \\
\text { os meses }\end{array}$ & $\begin{array}{l}\text { Sim, de todos } \\
\text { os meses }\end{array}$ & $\begin{array}{l}\text { Sim, de todos } \\
\text { os meses }\end{array}$ & $\begin{array}{l}\text { Sim, de todos } \\
\text { os meses }\end{array}$ \\
\hline 10 & $\begin{array}{l}\text { Quanto ao estabelecimento } \\
\text { de normas: a IES possui } \\
\text { regulamento específico para } \\
\text { o Programa Bolsa } \\
\text { Permanência Institucional? }\end{array}$ & $\begin{array}{l}\text { Ainda não foi } \\
\text { possível } \\
\text { pensar no } \\
\text { estabeleciment } \\
\text { o de normas } \\
\text { para o PBP. }\end{array}$ & Sim & Sim & Sim \\
\hline 11 & $\begin{array}{l}\text { Quanto à permanência: a IES } \\
\text { tem se preocupado em medir } \\
\text { a taxa de evasão e retenção } \\
\text { dos alunos, conforme os } \\
\text { objetivos do Decreto } \mathrm{n}^{\circ} \\
7.234 / 2010 ?\end{array}$ & $\begin{array}{l}\text { Outros } \\
\text { (estamos em } \\
\text { fase de } \\
\text { construção de } \\
\text { observatório } \\
\text { para medir } \\
\text { essas taxas) }\end{array}$ & $\begin{array}{l}\text { Sim, medimos } \\
\text { as taxas de } \\
\text { evasão e } \\
\text { retenção } \\
\text { semestralment } \\
\text { e }\end{array}$ & $\begin{array}{l}\text { Sim, } \\
\text { medimos as } \\
\text { taxas de } \\
\text { evasão } \quad \text { e } \\
\text { retenção } \\
\text { semestralmen } \\
\text { te }\end{array}$ & $\begin{array}{lr}\text { Sim, } & \\
\text { medimos } & \text { as } \\
\text { taxas } & \text { de } \\
\text { evasão } & \text { e } \\
\text { retenção } & \\
\text { anualmente } & \end{array}$ \\
\hline 12 & $\begin{array}{l}\text { Quanto ao desempenho: a } \\
\text { IES costuma acompanhar o } \\
\text { desempenho acadêmico dos } \\
\text { bolsistas do Programa Bolsa } \\
\text { Permanência Institucional? }\end{array}$ & $\begin{array}{l}\text { Sim, } \\
\text { acompanhamo } \\
\text { s o } \\
\text { desempenho } \\
\text { acadêmico } \\
\text { mensalmente }\end{array}$ & $\begin{array}{l}\text { Sim, } \\
\text { acompanhamo } \\
\mathrm{s} \quad \mathrm{o} \\
\text { desempenho } \\
\text { acadêmico } \\
\text { semestralment } \\
\text { e }\end{array}$ & $\begin{array}{l}\text { Sim, } \\
\text { acompanham } \\
\text { os o } \\
\text { desempenho } \\
\text { acadêmico } \\
\text { semestralmen } \\
\text { te }\end{array}$ & $\begin{array}{l}\text { Sim, } \\
\text { acompanham } \\
\text { os o } \\
\text { desempenho } \\
\text { acadêmico } \\
\text { anualmente }\end{array}$ \\
\hline 13 & $\begin{array}{l}\text { A IES analisa a relação entre } \\
\text { o desempenho e a } \\
\text { permanência dos alunos na } \\
\text { Instituição? }\end{array}$ & $\begin{array}{l}\text { Não } \\
\text { analisamos a } \\
\text { relação do } \\
\text { desempenho e } \\
\text { da } \\
\text { permanência } \\
\text { do aluno } \\
\end{array}$ & $\begin{array}{l}\text { Sim, } \\
\text { analisamos a } \\
\text { relação do } \\
\text { desempenho e } \\
\text { da } \\
\begin{array}{l}\text { permanência } \\
\text { do aluno }\end{array} \\
\end{array}$ & $\begin{array}{l}\text { Não } \\
\text { analisamos a } \\
\text { relação do } \\
\text { desempenho } \\
\text { e da } \\
\text { permanência } \\
\text { do aluno }\end{array}$ & $\begin{array}{l}\text { Sim, } \\
\text { analisamos a } \\
\text { relação do } \\
\text { desempenho } \\
\text { e da } \\
\text { permanência } \\
\text { do aluno }\end{array}$ \\
\hline 14 & $\begin{array}{lr}\text { Quanto à } & \text { avaliação dos } \\
\text { beneficiários } & \text { do Programa } \\
\text { Bolsa } & \text { Permanência } \\
\text { Institucional: } & \text { existem } \\
\text { mecanismos para conhecer a } \\
\text { opinião dos alunos sobre a } \\
\text { concessão do benefício } \\
\text { recebido? }\end{array}$ & Não & Parcialmente & Sim & Parcialmente \\
\hline 15 & $\begin{array}{l}\text { Quais mecanismos são } \\
\text { utilizados para a avaliação } \\
\text { dos alunos quanto à } \\
\text { concessão do benefício } \\
\text { recebido? }\end{array}$ & Não há & Questionário & $\begin{array}{l}\text { Fórum de } \\
\text { Assistência } \\
\text { Estudantil }\end{array}$ & $\begin{array}{l}\text { Questionário } \\
\text { e coleta de } \\
\text { dados } \\
\text { objetivos com } \\
\text { respostas }\end{array}$ \\
\hline
\end{tabular}




\begin{tabular}{|c|c|c|c|c|c|}
\hline & & & & & fechadas \\
\hline 16 & $\begin{array}{l}\text { Essas informações são } \\
\text { utilizadas para revisar o } \\
\text { planejamento do programa, o } \\
\text { regulamento, os editais e o } \\
\text { processo de concessão do } \\
\text { benefício do Programa Bolsa } \\
\text { Permanência Institucional? }\end{array}$ & Não há & Sim & Sim & Parcialmente \\
\hline 17 & $\begin{array}{l}\text { As informações obtidas } \\
\text { referentes à avaliação e ao } \\
\text { monitoramento são } \\
\text { exploradas para a elaboração } \\
\text { de estratégias institucionais } \\
\text { para a revisão do programa? }\end{array}$ & Sim & Sim & Sim & Sim \\
\hline 18 & $\begin{array}{l}\text { Existem outras dificuldades } \\
\text { que gostaria de relatar? }\end{array}$ & Não & Não & Não & $\begin{array}{lr}\text { Sim, o } & \text { o } \\
\text { recurso } & \text { é } \\
\text { escasso frente } \\
\text { a demanda } \\
\text { crescente. } \\
\text { Esse é o } \\
\text { desafio de } \\
\text { todas } \\
\text { IFES. }\end{array}$ \\
\hline
\end{tabular}

Fonte: Quadro elaborado pela autora com base na pesquisa (2018).

Logo, através do exposto, verifica-se que o monitoramento das ações de assistência estudantil presentes nas universidades pesquisadas é tidas, prioritariamente, com necessidades de melhorias ao longo do processo. Entretanto, corroboram positivamente com as demais universidades que estão na construção de seus modelos de monitoramento.

Posto isto, encerra-se esta sessão com o resumo dos principais pontos levantados a partir da análise do corpus da pesquisa: Inserção de uma instância superior para as discussões da Assistência Estudantil; Monitoramento das ações de assistência, sobretudo dos números de evasão e retenção dos beneficiários do programa bolsa permanência; Sistema integrado para o cruzamento dos dados; Participação dos estudantes nas tomadas de decisões quanto à Assistência Estudantil na universidade; Articulação entre as demais Pró-Reitorias.

\section{Considerações finais}

Com o presente trabalho foi possível verificar a importância do monitoramento e da avaliação na Política de Assistência Estudantil nas Universidades Federais brasileiras, no que tange à busca pela permanência dos graduandos, sobretudo quanto ao estabelecimento de monitoramento das 
ações desenvolvidas ao Programa Bolsa Permanência.

Na pesquisa, as Universidades Federais UFAC, UFS, UFU e UFV, articulam formas de monitoramento das ações de assistência estudantil, e ainda que em estágio inicial e de aprimoramento, estas resultam em dados para possíveis tomadas de decisões da gestão. A princípio as ações realizadas estão organizadas em síntese dos dados de aprovação, reprovação e evasão dos estudantes bolsistas; avaliação semestral do rendimento acadêmico do estudante; pesquisas de satisfação dos estudantes bolsistas e a análise de indicadores.

Em resumo, foram destacados os principais pontos a serem inseridos na política de monitoramento de uma instituição, como: i) Inserção de uma instância superior para as discussões da Assistência Estudantil ii) Monitoramento das ações de assistência, sobretudo dos números de evasão e retenção dos beneficiários do programa bolsa permanência; iii) Sistema integrado para o cruzamento dos dados; iv) Participação dos estudantes nas tomadas de decisões quanto à Assistência Estudantil na universidade; v) Articulação entre as demais Pró-Reitorias.

Outrossim, acreditamos que o resultado desta pesquisa contribuirá para o diagnóstico inicial de ações de monitoramento a serem implantados nas universidades federais, particularmente no Programa Bolsa Permanência, com intuito de construir um instrumento de monitoramento para que este facilite o processo nas tomadas de decisões dos gestores.

Devido à escassa literatura acerca do tema, faz-se ainda necessário o desenvolvimento de novas pesquisas sobre o assunto, de modo a tornar o debate sobre a avaliação e o monitoramento da Política Pública de Assistência Estudantil mais denso e consistente.

\section{REFERÊNCIAS}

ALVES, J. M. A assistência estudantil no âmbito da política de Ensino Superior Pública. Serviço Social em Revista, v. 5, n. 1. jul./dez. 2002. Londrina - PR: UEL, 2002. Disponível em: http://www.uel.br/revistas/uel/index.php/ssrevista. Acesso em: 03 ago. 2018.

ARRETCHE, M. T.S. Tendências no estudo sobre avaliação. In: RICO. E. M. (Org.). Avaliação de políticas sociais: uma questão de debate. São Paulo: Cortez, 2009. Acesso em: 06 nov. 2018.

BATTISTUZ, G. Z. Monitoramento e avaliação de políticas públicas de turismo: uma análise do Plano de Desenvolvimento do Turismo do Paraná 2008-2011. 2014. 188f. Dissertação (Mestrado em Políticas Públicas) - Universidade Estadual de Maringá, Maringá.

BRASIL. Decreto ${ }^{\circ} 7.234$ de 19 de julho de 2010. Dispõe sobre o Programa Nacional de Assistência Estudantil - PNAES. Brasília, 2010. Acesso em: 20 set. 2018.

BRITO, A. C. T. C. Institucionalização de uma política de monitoramento do Programa Bolsa Permanência da Universidade Federal da Grande Dourados (UFGD). Dissertação (Mestrado 
em Administração Pública) - Universidade Federal da Grande Dourados, 2018. Disponível no Repositório Institucional da UFGD em: <https://portal.ufgd.edu.br/setor/biblioteca/repositório>.

CONDÉ, E. S. Abrindo a Caixa: dimensões e desafios na análise de Políticas Públicas. Revista Pesquisa e Debate em Educação, v. 2, n. 2, 2013. Acesso em: 16 jul. 2018.

CRESWELL, J. W. W. Projeto de pesquisa: métodos qualitativo, quantitativo e misto. 2. ed. Porto Alegre: Bookman, 2010. Acesso em: 20 out. 2018.

FERNANDES, F. S. Políticas públicas e monitoramento na Educação Infantil. Estudos em Avaliação Educacional, v. 25, n. 58, p. 44-72, 2014. Acesso em: 10 jun. 2018

SECCHI, L. Políticas públicas: conceitos, esquemas de análise, casos práticos. São Paulo: Cengage Learning, 2010. Disponível em: Acesso em 23 jun. 2018.

TCU. TRIBUNAL DE CONTAS DA UNIÃO. Relatório de auditoria operacional em açõesda rede federal de educação profissional, científica e tecnológica. Brasília: TCU/Seprog, 2012. Disponível em: Acesso em jun. 2018.

\section{Como referenciar este artigo}

BRITO, Adriana Carla Teixeira da Costa, COSTA, Ana Karoliny Teixeira da e ALMEIDA, Vera Luci de. Gestão universitária: políticas comparadas de monitoramento do programa bolsa permanência em universidades federais brasileiras. Revista Ibero-Americana de Estudos em Educação, Araraquara, v. 14, n. esp. 3, p. 1862-1875, out., 2019. E-ISSN: 1982-5587. DOI: 10.21723/riaee.v14iesp.3.13036

Submetido em: 25/03/2019

Revisões requeridas: 22/04/2019

Aceito em: 17/05/2019

Publicado em: 30/08/2019 